ICRHKeny

International
centre for
for

Reprofoctive
Health - Mombasa
Universidad

deValparaíso CHILE
$\mathrm{E} \cdot \mathrm{S} \cdot \mathrm{R} \cdot \mathrm{C}$

ECONOMIC

RSOCIAL

COUNCIL DFID

\title{
Experiences and lessons learned from influencing the social determinants to reduce child under-nutrition in Kenya
}

\section{Dr Mary Amuyunzu-Nyamongo}

Senior Researcher/Consultant, International Centre for Reproductive Health (ICRH), Kenya

Pathways to better nutrition Series 2

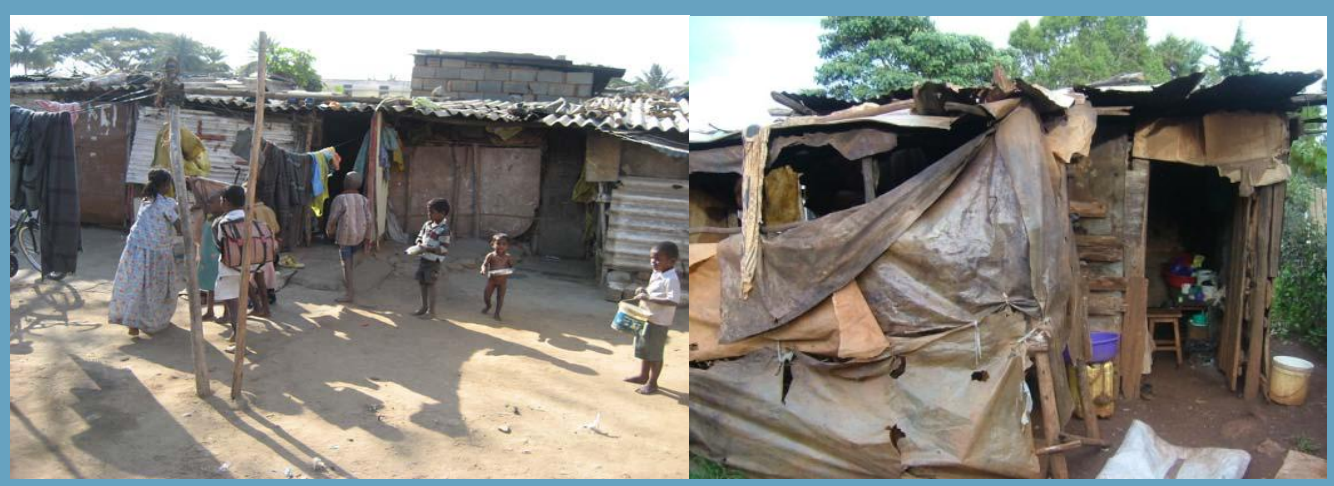


Cover photo: @ African Institute for Health \& Development

Published by the NICK Project research partnership

(c) 2011 Institute of Education, University of London

Urbanisation can bring many benefits but in many cities the rate of change has been so fast and so dramatic that local and national governments have been unable to cope. Urban growth has outpaced their ability to build essential infrastructures leading to widespread social inequity and social stratification environmental degradation, heavy migrant inflows, and a breakdown of the social support systems and networks. In these poor urban areas there is a strong and well established link between the various dimensions of disadvantage and child malnutrition (both undernutrition and overnutrition).

NICK (Nutritional Improvement for children in urban Chile and Kenya) is a three year study that started in October 2010 with funding from the UK Government Department for International Development (DFID) through the Economic and Social Research Council. This study helps the cities of Mombasa in Kenya and Valparaíso in Chile reduce child malnutrition using participatory action research to broaden stakeholder participation at municipal level to change the social determinants. These determinants control the everyday conditions in which people are living and include education, income, working conditions, housing, neighbourhood and community conditions, and social inclusion. It is envisaged that this study will contribute to existing knowledge and also serve as a useful guide for action not only in Kenya and Chile but also in other countries with high levels of child malnutrition.

The partners

The research team is led from the Department of Humanities and Social Science, Institute of Education, University of London and the research is being developed collaboratively with partners in Chile and Kenya.

Lead partner

The Department of Humanities and Social Science, Institute of Education, University of London:

Dr. Pat Pridmore, Dr Tristan McCowan and Professor Roy Carr-Hill

Collaborating partners

Department of Public Health of the University of Valparaíso: Prof. Gabriela Charnes Cars and Dr. Beatriz Salgado Diez

The International Centre for Reproductive Health (ICRH), Kenya: Dr. Mary Amuyunzu-Nyamongo and Mr. Daniel Lang'o

\section{Disclaimer}

The research on which this paper is based was commissioned by the NICK Project (http://nick.ioe.ac.uk). The views expressed are those of the author(s) and not necessarily those of the NICK Team.

ISBN 978-1-906648-11-4

\section{The NICK Project}

Department of Humanities and

Social Science

Institute of Education
20 Bedford Way

London

WC1H OAL

United Kingdom
Tel: + 44 (0) 2030738341

Website: http://nick.ioe.ac.uk

Email: p.pridmore@ioe.ac.uk 


\title{
Experiences and lessons learned from influencing the social determinants to reduce child under-nutrition in Kenya
}

\section{Paper presented at the first research team workshop in London, December 2010.}

\author{
Dr Mary Amuyunzu-Nyamongo ${ }^{1}$ \\ Senior Researcher/Consultant, International Centre for \\ Reproductive Health (ICRH), Kenya
}

Pathways to better nutrition Series No 2

\footnotetext{
${ }^{1}$ African Institute for Health \& Development, $2^{\text {nd }}$ Floor Wood Avenue Court, P.O. Box 4525900100, Nairobi. Email: mnyamongo@aihdint.org or manyamongo@yahoo.com
} 


\section{Summary}

Using a social determinants of malnutrition lens allows us to assess factors that determine child malnutrition and ill-health in urban poor settings. This paper draws on examples of studies and interventions carried out in poor urban areas in Kenya to identify key instruments that have the potential to shift the current status of high levels of under-nutrition and increasing over-nutrition among children. The process proposed would require multiple actors, community ownership and leadership, political will and a focus on life-cycle approach. 


\section{Table of contents}

1. Introduction $\quad 6$

$\begin{array}{ll}\text { 2. The urban context } & 7\end{array}$

3. Social determinants of child nutrition in poor urban settings $\quad 8$

4. Examples of interventions to address child nutrition deficiencies in Kenya 9

4.1 The Makueni community-based Applied Nutrition Project 10

4.2 UNICEF Nutrition project $\quad 10$

5. New opportunities for nutrition surveillance and data in urban areas of Kenya

6. Possible interventions 12

References $\quad 14$ 


\section{Introduction}

The Kenyan urban population is now more than eight times higher than the estimated 1.6 million in 1963, and represents some 35 percent of the nation's population compared to only 7 percent in 1963. By 2020 this figure is expected to reach nearly 50 percent. While the total population of urban dwellers has grown very rapidly, the share of poor populations residing in low-income high-density urban households is proportionally higher, representing the vast majority (APHRC, 2002). There is further evidence that urban food poverty has been on the increase. The Kenya National Bureau of Statistics (KNBS, 2007) report from the 2005/06 Kenya Integrated Household Budget Survey (KIHBS) established that urban food poverty increased from 38.8 percent in 1997 to 40.5 percent by 2006; a situation which has precipitated food and nutrition insecurity. Although rural areas report higher levels of food poverty (49.7 percent) compared to urban areas (34.4 percent), these figures camouflage huge disparities in urban areas between the non-poor and poor areas. The critical food poverty was calculated at 15 percent for urban and 22 percent for rural areas (Ndirangu, 2010).

The Kenya Food Security Steering Group (KFSSG) undertakes food insecurity and vulnerability surveys in a bid to assess the food situation and advise public policy makers on appropriate interventions. Although the surveys have provided important inputs towards food policy formulation and programme design aimed at curbing food insecurity, the focus has been biased towards rural areas with high-density urban households receiving little or no attention. ${ }^{2}$ It is assumed that the food situation worsened following the food price crisis of 2008 in the domestic and international markets, which had negatively affected both urban and rural households who are netbuyers of food. The KFSSG estimated that in 2008 about 10 million people in Kenya were food insecure and vulnerable to domestic and external shocks. Although 6.5 million people in rural areas were catered for through relief food and other instruments, the remaining 3.5 million in urban areas did not have any form of immediate support. $^{3}$

In response to this, a rapid appraisal was conducted by KFSSG in December 2008 in Nairobi and Mombasa urban areas to assess the basic determinants of food insecurity and nutritional vulnerability and to identify both challenges and opportunities for designing a comprehensive livelihood and food security and nutrition baseline survey. The results demonstrated that the urban population, especially within the high-density urban households, is often vulnerable to food insecurity due to a variety of risk factors including loss of income, low incomes and high cost of living. For example, in urban markets, maize prices rose by an estimated 133 percent while the average household incomes declined by about 21 percent within the same period. These economic shocks placed a heavy burden particularly on high-density urban households making the availability of food unaffordable, hence increasing food insecurity and nutritional deficiency status (Kenya Food Security Meeting (KFSM) monthly reports, 2010).

In an attempt to cushion the vulnerable against rising food prices, the Government introduced a generalized maize subsidy scheme in November 2008. The scheme had two components: the first was a policy to sell maize to millers through the National Cereals and Produce Board (NCPB) at belowmarket prices. The millers were then expected to passon the subsidy and sell the flour at below prevailing retail prices to everyone regardless of

\footnotetext{
${ }^{2}$ Derived from a KFSSG and WFP concept note for an urban survey.

${ }^{3}$ These estimates are compiled based on data for the Early Warning System (EWS), which are derived from rainfall patterns. The data are updated every six months.
} 
income status. The cost of the scheme was estimated to be Kshs 23.4 billion in subsidy and tax foregone in the fiscal year 2008/09. As a result of design flaws, the scheme was found to be too expensive and also created distortions in the maize market and diversion of maize from NCPB for unintended purposes. As a generalized subsidy scheme the programme was designed to be proportional, conferring flatbenefits to the rich and the poor, although the poor would have likely gained more as a proportion of their income or expenditures. After a critical analysis, the scheme was withdrawn by the Government, which made a commitment to develop an alternative more efficient and targeted scheme.

The second action was to provide food subsidies to urban poor, on a pilot basis, to assess the appropriate targeting and delivery mechanisms in selected urban poor areas of Nairobi, Mombasa and Kisumu. This pilot was to be implemented by the government in partnership with Oxfam and the World Food Programme (WFP) in 2009. The cash transfer for poor households was put at Kshs 1,500 per month (within the urban food poverty line estimated at Kshs 1,490). Although it was considered an important learning process, government funding has not come through. The WFP and Oxfam/World are currently implementing the programme in limited informal settlements of Nairobi. An evaluation is planned for 2010/11 to assess the programme for wider learning.

Based on the framework developed by UNICEF in 1990, this paper explores the key factors that influence child over and under-nutrition: immediate; underlying; and basic factors and assesses how these have been addressed in Kenya. For children, the immediate causes are inadequate dietary intake and disease. When lack of food and disease are combined, the child's risk of developing under-nutrition increases. Three main underlying causes have been identified: (i) inadequate access to nutritious food and/or utilization of available food; (ii) inadequate childcare practices; and (iii) inadequate access to quality health services (Pridmore and Carr-Hill, 2010).

\section{The urban context}

The urban population in Kenya grew from 3.8 million in 1989 to 9.9 million in 1999 , constituting 34 percent total population. For instance, Nairobi's population was only 120,000 in 1948 (Muwonge, 1980) and by 1999 it was estimated at 2.3 million (Republic of Kenya (ROK, 2001). Women form about 49 percent of the urban population. These population increases have been accompanied by a rapid rise in poverty levels. It is estimated that about 60 percent of Nairobi residents are poor and live in congested informal settlements that occupy only 5 percent of the residential land area (APHRC, 2002).

By their very nature, informal settlements are replete with poor environmental factors that predispose their inhabitants to poor health outcomes. These settlements are usually illegal or quasi-legal and built on marginal lands in contravention of planning and building regulations (United Nations, 1996). They do not receive the usual services such as supply of potable water, wastewater drainage, refuse collection and sewerage services from the urban governments. These conditions expose residents, especially children, to various health risks including malnutrition. For example, the children who appear to be most vulnerable to poor nutritional outcome and food insecurity amongst those living in households in Nairobi slums are those with some or all of the following characteristics: residence in the poorest households; with a single parent (the mother) as the main provider; and co-residence with a large number of children (Kimani-Murage et al., 2010).

The epidemiological profile of the informal settlements reflects the poor living conditions. In terms of child health the African Population and Health Research Centre (APHRC, 2002) established that diarrhoea affected 31 percent of the children under three years of age in the informal settlements, which was more than double the rate of Nairobi as a whole (13 percent), and was considerably higher than the rates for other urban and rural areas. This 
was despite higher educational attainment - about 73 percent of all the respondents had completed primary school or been to secondary school, compared to only 46 percent for rural residents and 68 percent for residents of other urban areas. Measles coverage was found to be lower in the informal settlements compared to Nairobi and other urban areas. In addition, the infant mortality rate (IMR) was higher in Nairobi's informal settlements $(91 / 1000)$ compared to $39 / 1000$ in the non-slum parts of Nairobi and 76/1000 in rural Kenya.

\section{Social determinants of child nutrition in poor urban settings}

The urban advantage (due to better facilities and access to better services) has been shown to mask enormous disparities between the poor and the non-poor in urban areas of subSaharan Africa (Fotso, 2006). Demographic and Health Surveys (DHS) indicate that the urban poor in sub-Saharan Africa have less access to health services, and consequently exhibit higher mortality rates than residents from other population sub-groups including rural residents (Essendi et al., 2009).

This paper draws from the premise that proper nutrition is every child's right, and this has been enshrined in Kenya's constitution (promulgated in August 2010). Malnutrition is thus a social injustice because evidence shows that well-nourished children are generally healthier, more active, learn better in school and have a greater chance of fulfilling their potential (UNICEF, 2009). In Kenya, the challenges affecting the nutrition sector of relevance to children include:

(i) low levels of exclusive breast-feeding;

(ii) poor complementary feeding;

(iii) poor child care practices;

(iv) high levels of micronutrient malnutrition that impede proper growth and development;

(v) lack of a policy and implementing framework for nutrition interventions in the country; and

(vi) weak capacity in-country to manage nutritional aspects of emergencies.

In addition, cultural aspects, including beliefs and food preparation and consumption practices, determine nutrition to some extent. These include approaches to food preparation and perceptions regarding the appropriate food for children and other household members. This is an area that remains largely unexplored more so in urban areas.

There is a great need for developing and scaling up a coordinated and technically sound nutrition and care package for people living with and households affected by HIV and AIDS (UNICEF, 2009; KNBS \& Macro, 2010; Kabubo-Mariara, 2009; Marinda, 2006). There is evidence that the nutritional status of children infected or affected by HIV and AIDS is lower than that of other children of similar age.

Although it is not possible to estimate the prevalence of lack of food in slum communities, predictors of nutritional status indicate high prevalence of food-related deficiencies. A study conducted in Korogocho found that two-thirds of the population was unable to meet its daily energy requirements, 40 percent of the children aged between 6 months and 5 years were underweight, 28 percent were stunted and 5.4 percent were wasted (Mwangi \& Foeken, 1996). The KDHS (2008/9) data show that 35 percent of children under 5years were stunted while 14 percent were severely stunted, 7 percent were wasted and 2 percent severely wasted (KNBS \& Macro, 2010).

Children of the urban poor are continually exposed to higher risks of fatal diseases due to inequitable income distribution and access to social services. Evidence generated through a longitudinal study in Nairobi has shown that child mortality in the slums is 2.5 times greater than in other areas of the city. For instance, the prevalence rate of diarrhoea in children under three years of age in the informal settlements was more than double that of Nairobi as 
a whole (Taffa et al., 2006). The IMR in Nairobi's informal settlements is higher than in any other parts of Kenya. In 2000, the IMR was 91/1000 in Nairobi slums, 39/1000 in Nairobi as a whole, $57 / 1000$ in urban Kenya, 76/1000 in rural Kenya, and 74/1000 in Kenya as a whole.

Poverty is a key determinant of undernutrition in poor urban areas. Unemployment, irregular and unskilled livelihood opportunities limit financial capabilities to access nutritious child food and demand for quality healthcare at household level. Mothers engaged in causual day wage work have major challenges of childcare, consequently affecting the nutritional status of children (Amuyunzu-Nyamongo et al., 2009). In a study conducted in a Nairobi informal settlement, mothers identified childcare as one of their key challenges. They noted that although they wanted to engage in income generating activities, their key constraint was 'who to leave their children with as they went out in search of employment.' This was a major concern for those with children under 3 years of age who were not yet eligible for preschool. In response to this need, the project established a daycare centre where the mothers would leave their children during the day as they searched for or performed their daywage duties (Amuyunzu-Nyamongo et al., 2009).

Evidence is beginning to emerge of over-nutrition in slum areas. This is mainly due to the fact that not all slum residents are poor, uneducated and migrants from rural communities, even though they live in the same environments. Differences in income, migration status, education and ethnic background influence diet with those more able economically providing high sugar, high fat and high salt foods to their children (Amuyunzu-Nyamongo, 2010).

One key challenge to poor households is the lack of access to social capital which has been found wanting in urban poor areas. A study conducted by Amuyunzu-Nyamongo \& Ezeh (2005) established that: (i) there was reduced likelihood for people to provide support towards access to food; (ii) social support was more readily available during a death and/or serious illness; (iii) support was highly reciprocal. Across the four communities studied, the qualitative discussions consistently showed that no form of support existed for individuals or households who lacked food and sometimes residents could go for days without food. The authors concluded that lack of food, being a common problem in these communities, which individuals endeavour to resolve on a daily basis, was not considered a crisis. This observation is not unique to this group of people. In Voices of the Poor (World Bank, 2003), a young man from Zambia observes that when food was in abundance relatives used to share it but things have changed due to food shortages to the extent that even relatives do not assist. This shows that with increasing stress on the capacity of households to cope with poverty, there is likelihood of reduced social capital to cushion those who need food, especially in urban areas.

\section{Examples of interventions to address child nutrition deficiencies in Kenya}

The need to focus on child nutrition was given momentum at the turn of the decade with the Millennium Development Goal (MDG) 1 on poverty. The two indicators of "percent of children below height for age" and "percent children under weight" at 16.1 percent and 6.7 percent, respectively illustrate that the country needs to do more to eradicate extreme poverty and hunger (GoK, 2010). In Kenya, the main interventions to address child nutrition have been in the form of: (i) medical interventions; (ii) emergency response (during a crisis and in refugee camps); (iii) school feeding (but the target for such programmes is higher for 0-5 year olds). Although there is evidence of effectiveness of interventions targeting children in the country, this is skewed towards rural areas. In this section, two nutrition programmes are presented: (i) UNICEF Nutrition Project; and (ii) community-based intervention in Kibwezi by the African Medical and Research Foundation (AMREF). The main aim of this section is to illustrate strategies for successful implementation that could inform NICK. 


\subsection{The Makueni community-based Applied Nutrition Project}

The overall goal of this Project by AMREF is to increase household food security and improve nutrition security in three divisions of Makueni district - namely Kibwezi, Makindu and Mtito-Andei. Specific objectives are to: (i) increase food production of households by 60 percent; (ii) increase the production by households of an improved breed of small livestock; (iii) increase by 20 percent (current estimate is $<8$ percent) the percentage of mothers practising exclusive breastfeeding of their infants until 6 months of age; (iv) increase the percentage of mothers practising appropriate weaning practices by 30 percent; (v) increase accessibility to clean water and reduce the distance to water source from the estimated average of $5 \mathrm{~km}$ to $2 \mathrm{~km}$. There is, however, no specific mention of reduction in the prevalence of under-nutrition in the objectives.

Various stakeholders are involved in the planning and implementation of this project: the communities through their traditional and administrative structures; district, divisional and sub-divisional development committees made up of members from all sectoral ministries; people's representatives and all other relevant development partners; the line ministries' branch offices at all levels; non-governmental organizations (NGOs) including Danish International Development Assistance (DANIDA); the Kenya Agricultural Research Institute (KARI); and the Kenya Forestry Research Institute (KEFRI). Some of the key strategies utilized in the project are:

(i) increasing crop production through supporting the production of drought tolerantcrops and establishing group seed banks;

(ii) increasing household income through credit access - by establishing a credit facility, small livestock improvement (goat and chicken) and credit for oxen and plough;

(iii) improving water supply and sanitation: digging shallow wells and in some cases extending pipes, roof catchment and other forms of water harvesting;

(iv) implementing nutrition education through community growth monitoring and heath promotion by community health workers; and

(v) food for work: the projects identified are water supply, building a maternity ward, irrigation schemes and school maintenance as key actions.

An external evaluation established that adequate information to assess outcomes and impact was lacking because indicators to measure the inter-linkages between outputs, outcomes and impact had not been well established. From information gathered from four community-based surveys, it was evident that there had been no significant decline in nutritional status, but the situation seemed to have fluctuated somewhat depending on the drought situation. However, hospital and other health facility records and information gathered from health personnel indicated a significant drop in the number of kwashiorkor and marasmus cases. The evaluators noted that this could have been due to the measurements adopted that had limited sensitivity. They proposed further communitybased surveys.

\subsection{UNICEF Nutrition project ${ }^{4}$}

The UNICEF Nutrition programme aims to increase access to and use of basic social services with particular attention to marginalized and vulnerable populations; enhance capacities of key national and local institutions for improved governance; reduce further spread of HIV and improve the quality of life of those affected by HIV/AIDS; and enhance institutional and technical capacity for disaster management (preparedness and response), policy formulation and implementation. It directly relates to the MDGs 1, 4, 5 and 6 . The programme focuses its efforts at the national and district levels. At national level,

\footnotetext{
${ }^{4}$ It is not clear whether this project has been evaluated.
} 
support is provided to the development of the National Food and Nutrition Policy and even more importantly, the translation of the policy into a national strategy. The programme also addresses the current inadequacy of technical guidelines, policy documentation and monitoring structures in such key areas as HIV/AIDS, micronutrients and the management of malnutrition.

\section{Key strategies}

At district level, the programme supports a comprehensive and inter-sectoral approach to addressing nutrition and malnutrition. It prioritizes the populations in the eleven arid and semi arid districts of northern and north-eastern Kenya and slums of Nairobi to ensure increased access to essential nutrition related support. This involves support to and dialogue with a broad range of stakeholders to address some of the issues that currently increase the nutrition-related vulnerability of populations in arid areas including access to food and appropriate childcare practices.

The programme increases the engagement with partners in agriculture and education sectors and aims to strengthen collaboration and integration where nutrition interventions can be delivered through the health sector. A number of key strategies are being used and these have proven to influence malnutrition. These include a focus on promotion of optimal practices related to infant and young child feeding, supplementation and fortification with specific micronutrients and appropriate nutritional management of individuals with specific needs including those already malnourished and those affected by HIV and AIDS.

Of critical importance to logical and strategic decision-making is a functional nutrition information system. Efforts are being made to develop a nutrition information system that will support long-term monitoring and evaluation and also ensure that adequate information is available in food insecure populations to facilitate timely interventions during periods of crisis.

The programme also focuses on training. Mentoring and supportive supervision is used to develop skills and to provide opportunities for exchange of experiences. There is an even greater focus on training for trainers in specific focus areas such as management of malnutrition to ensure a broader reach and greater sustainability of the programme activities.

The programme has increased its engagement with the private sector and research institutions to support the ongoing development of nutrient dense products. Issues related to special nutritional needs of specific groups, scientific analysis, quality control and certification are being addressed.

\section{New opportunities for nutrition surveillance and data in urban areas of Kenya}

There are three studies that would provide information on the food and nutrition situation in informal settlements to complement the NICK Project in Kenya: (i) the comprehensive urban food and nutritional security baseline survey; (ii) Concern Worldwide Surveillance in informal settlements; and (iii) urban subsidy programme.

(i) The KFSSG and the World Food Programme initiated a study in July 2010 to understand the nature of the 'high-density urban households' food and nutritional security status in order to provide public policy guidance and advice on likely interventions. This is a nationwide study that covered 35 urban centres in Kenya including Mombasa. The results are expected in 2011 and would inform the NICK Project. Of relevance to the NICK Project would be the nutritional assessment in which the prevalence of malnutrition was assessed in children aged 6 to 59 months based on the following parameters: age, sex, weight in kilograms (to the nearest 100g), height in centimetres (to the nearest millimetre), presence 
or absence of oedema and the Mid Upper Arm Circumference (MUAC). Given the vast coverage of the study, this would be the largest survey conducted in Kenya on urban food and nutrition.

(ii) Concern Worldwide has established a surveillance system in Nairobi and Kisumu to monitor child nutrition among other health indices entitled Urban Nutrition Infant and Young Child Feeding Practices (IYCF) (The Kenya Nutrition bulletin April - June 2010). Since the set up of the surveillance systems in January 2010 in Kisumu and Nairobi, Concern Worldwide has conducted two rounds of surveillance (March and May 2010) in three selected slum communities: Korogocho and Mukuru (Nairobi) and Nyalenda (Kisumu). Mothers with children $<6$ months were asked whether they exclusively breastfed their children in the last 24 hours. Although the average reported level of breastfeeding at 47.7 percent across the 3 areas was higher than the national figure of 32 percent, there are indications that a majority of the caretakers cease breastfeeding infants earlier than recommended. According to the respondents, breast milk insufficiency and return to work were the main reasons cited for cessation of exclusive breastfeeding. Data on the introduction of complementary food indicate that majority of caregivers introduce food earlier than recommended (before the recommended six months): 53.9 percent in Korogocho, 52.4 percent in Mukuru and 54.1 percent in Nyalenda slum in Kisumu introduced other foods besides breast milk before their infants had reached 6 months old. The poor environment coupled with limited awareness and poor hygiene practices are the major causes of concern for high rates of morbidity and the ensuing acute malnutrition. This brief indicates that in the long-term the surveillance system will provide critical data that have hitherto been lacking on poor urban areas.

(iii) Urban subsidy programme: This programme, implemented by Oxfam/Concern Worldwide and WFP is under evaluation. The results are expected in 2011. It is anticipated that the results would be illustrative of the impacts of cash transfers to poor households. Evidence from other studies shows that cash transfers have positive impacts on child education and nutrition.

\section{Possible interventions}

For interventions targeting child nutrition to make a difference in poor urban areas, they must address the immediate, underlying, and root causes. This section provides suggestions on interventions for consideration by NICK and other programmes.

\section{Immediate measures:}

- Increase access to food: this would require interventions that improve household income to allow for the purchase of food. This is a major barrier considering that most urban people are net purchasers of food.

- Increased access to health services through voucher schemes and other forms of subsidies. Although the government of Kenya has a policy of free healthcare for children under5 years, drug and supply shortages force households to spend out-ofpocket money to access care.

\section{Underlying}

- Improve daily living conditions, including the determinants for poor health and nutrition - ensuring access to clean water for consumption and a clean environment for children are critical interventions.

- Use of community structures, including the community health strategy, to implement health promotion interventions such as education and advocacy for proper nutrition and diets for children.

\section{Root causes}


- It is critical that informal settlements become part and parcel of country and national development plans. The current scenario where such settlements are largely ignored has engendered the disparities in health and nutrition outcomes articulated in this paper.

- Address access to 'harmful foods' that are high in sugar, fat and salt. Marketing and sale of such food should be regulated and incentives introduced for households to consume more healthy foods in the form of vegetables and fruits.

- Implement social protection strategies that target poor and vulnerable children. These could be in the form of cash transfers, supplementary feeding and school feeding. The plight of younger children (those not of pre-school age) in poor households should be addressed.

The NICK Project will address some of the issues identified above. It is critical, however, for more evidence to be generated in urban areas in Kenya and other parts of sub-Saharan Africa on comprehensive approaches to addressing child nutrition among poor households. 


\section{References}

African Population and Health Research Centre. (2002) Population and health dynamics in Nairobi's Informal Settlements. Nairobi: African Population and Health Research Centre.

Amuyunzu-Nyamongo, M. (2010). Need for a multi-factorial, multi-sectorial and multidisciplinary approach to NCD prevention and control in Africa. Global Health Promotion 2010 17: 3. Pp31-32.

Amuyunzu-Nyamongo, M. \& Ezeh, A.C. (2005) A qualitative assessment of support mechanisms in informal settlements of Nairobi, Kenya. Journal of Poverty 9(3): 89-107.

Amuyunzu-Nyamongo, M., Oyugi, R.A. \& Okeng'o, L.N. (2009). Addressing social determinants of health in a Poor Urban Setting in Nairobi Kenya: Using a Health Promotion Approach. In Amuyunzu-Nyamongo, M. \& Nyamwaya, D.O. (eds) Evidence of Health Promotion Effectiveness in Africa. Nairobi, Kenya.

Essendi, H., Nyovani, J.M, Kavao, M., Fotso, J-C. \& Mutua, M. (2009) Synergistic relationship between child morbidity and malnutrition among the urban poor. APHRC. lussp 2009.princeton.edu/download.aspx?submissionld=92565

Fotso, J-C. (2006) Child health inequities in developing countries: differences across urban and rural areas. International Journal for Equity in Health 2006, 5:9 doi:10.1186/14759276-5-9

GoK (2010) Kenya Millennium Development Goals Status Report 2010. Government of Kenya Printers.

Kabubo-Mariara, J., Karienyeh, M.M. \& Mwangi, F.K. (2008) Child Survival, Poverty and Policy Options from DHS Surveys in Kenya: 1993-2004. PMMA Working paper 200801.

Kimani-Murage, E. W., 1 Holding, P.A., Fotso J-C, Kahurani, E.N., Madise, N.M., Ezeh, E.C. \& Zulu, E.M. (2010) Food Security and Nutritional Outcomes of Urban Poor Orphaned Children in Nairobi, Kenya. J. Urban Health. Oct 14.

KNBS \& MACRO, I. (2010) Kenya Demographic and Health Survey 2008-09. In: KNBS \& MACRO, I. (eds.). Calverton, Maryland: KNBS and ICF Macro.

Marinda, P. A. (2006) Child-mother nutrition and health status in rural Kenya: the role of intra-household resource allocation and education. International Journal of Consumer Studies, 30, 327-336.

Muwonge, J. W. (1980) "Urban policy and patterns of low-income settlement in Nairobi, Kenya", Population and Development Review, 6:595-613.

Mwangi, A. M., \& Foeken, D. W. J. (1996). Urban agriculture, food security in low-income areas of the city of Nairobi, Kenya. African Urban Quarterly. Special issue: Urban Agriculture in Africa, 111, 170-180.

Ndirangu, L. (2010) Poverty, risk and vulnerability in Kenya. Unpublished Report.

Pridmore, P. \& Carr-Hill, R. (2010) Tackling the drivers of child under nutrition in developing countries: what works and how should interventions be designed? Submitted 24 August 2009: Accepted 13 May 2010.

Republic of Kenya, (2001) 1999 Population and Housing Census, volume I, Nairobi: Central Bureau of Statistics. 
Taffa, N., Chepg'eno, G. \& Amuyunzu-Nyamongo, M. (2005) Child morbidity and health care utilization in the slums of Nairobi, Kenya. Journal of Tropical Paediatrics 51(5): 279-284.

United Nations (1996) State of the World Population 1996, New York: United Nations.

World Bank. (2003). Voices of the poor. www.worldbank.org/poverty/voices/ listenfindings.htm 


\section{NICK}

Department of International and

Lifelong Education

Institute of Education

20 Bedford Way

London WC1H OAL

United Kingdom

Tel: + 44 (0) 2030738341

Email: p.pridmore@ioe.ac.uk

Website: http://nick.ioe.ac.uk

ISBN 978-1-906648-11-4 